\title{
The Rate of Anti-Chlamydia Pneumoniae IgG and IgA Antibodies Among Patients With Coronary Heart Diseases in Diyala Province, Iraq
}

\author{
Abbas Abood Al-Duliami, Asmaa Haseeb Hwaid ${ }^{*}$, Fatin Ali Al-Chalabi \\ Department of Biology, College of Education for Pure Science, Diyala University, Diyala Province, Iraq
}

Email address:

dra_bbas@yahoo.com (A. A. Al-Duliami), asmaa.haseeb@ymail.com (A. H. Hwaid), fatin.ali41@yahoo.com (F. A. Al-Chalabi)

To cite this article:

Abbas Abood Al-Duliami, Asmaa Haseeb Hwaid, Fatin Ali Al-Chalabi. The Rate of Anti-Chlamydia Pneumoniae IgG and IgA Antibodies Among Patients With Coronary Heart Diseases in Diyala Province, Iraq. American Journal of Health Research.

Vol. 3, No. 3, 2015, pp. 121-124.doi: 10.11648/j.ajhr.20150303.11

\begin{abstract}
Background: Chlamydia pneumoniae is found worldwide, it causes acute respiratory infection, especially atypical pneumonia. High prevalence of past infection with Ch. pneumoniae have been found in developing countries that may has a role in pathogenesis of coronary heart disease. Objective: The present study was sought todetermined the rate of anti- $C h$. pneumoniae $\operatorname{IgG}$ and $\operatorname{IgA}$ antibodies among patients with coronary heart diseases in Diyala province, Iraq. Material and Methods: This study was conducted during the period from November/ 2013 to December/2014. 91 Participants were included; 45 patients with coronary heart disease (myocardial infarction, angina, and atherosclerosis) who were chosen according to clinical criteria and 46 apparently healthy individuals as control group. The mean age of the patients was $(59.20 \pm 11.45)$ years with an age rang (40-90) years, and for the controls, and the mean age was $(35.43 \pm 8.67)$ years with an age rang (32-86) years. Detection of anti- Ch. pneumoniae IgG and IgA antibodies was done by Enzyme - Linked Immunosorbant Assay (Nova Tec immundiagnostica GmbH, Germany). Results: The present results study show that the positivity rate of anti-Ch. pneumoniae IgG antibodies was significantly higher among patients compared to controls $(66.67 \%$ vs $54.35 \%, P \leq 0.05)$. While, the seroprevalence of anti- Ch. pneumoniae IgA antibodies among patients and controls was $24.44 \%$ and $13.04 \%$ respectively, this results showed that there is a statistically significant association between Chlamydia pneumoniae and CHD, P $\leq 0.05$. Conclusion: The presence of anti-Ch. pneumoniae IgG and IgA are significantly associated with CHD patients in Diyala province.
\end{abstract}

Keywords: Coronary Heart Diseases, Anti-Ch. Pneumoniae IgG and IgA, Diyala

\section{Introduction}

Chlamydia pneumoniae is a major cause of human respiratory diseases among children and adult. It is a ubiquitous Gram's negative obligate intracellular pathogen that is responsible for $5-10 \%$ of pneumonia cases in adult worldwide [1]. Ch. pneumoniae also can survive and multiply within the cells of the human vascular wall and their association with coronary heart diseases (CHD) has been reported earlier [2,3]. CHD is the most common type of heart disease that remains a major cause of morbidity and mortality in the industrialized world and become increasing in developing countries [4]. In addition to Ch. pneumoniae, several infectious agents that resulting in chronic infection such as Helicobacter pylori, Cytomegalovirus and Herpes Simplex Virus (HSV), have been a probably related with
CHD or atherosclerosis by contribute to increases risk of the pathogenesis of CHD [5].

The association of $\mathrm{Ch}$. pneumoniae with atherosclerosis and coronary heart disease has been based upon 4 research areas; seroepidemiological studies, detection of the pathogen in diseased arteries, experimental studies in vitro and in animal models, and human intervention trials with antibiotics $[5,6,7]$. An overwhelming number of seroepidemiological studies have suggested that $C h$. pneumoniae as detected by the presence of their antibodies may be related to the development of atherosclerotic disease [8,9,10,11]. In this context, a significantly higher seropositivity to $C h$. pneumoniae immunoglobulin $\operatorname{IgA}$ and $\operatorname{IgG}$ in patients with $\mathrm{CHD}$, diabetic patients with unstable angina, young patients 
with stroke and patients with acute myocardial infarction $[12,13,14,15]$. Moreover, the polymerase chain reaction (PCR) which is highly precise laboratory tool has also been used to identify Ch. Pneumonia DNA in atherosclerotic plaques and in patients with CHD [16,17].

It has been suggested that chronic infection of $C h$. pneumoniae may contribute to the development of CHD by increasing the concentrations of acute phase reactants such as C-reactive protein, heat shock proteins 60, fibrinogen, inflammatory markers such as interleukin7 and sialic acid which are predictors of CHD $[18,13,19]$. Furthermore, it has been demonstrated an association between Chlamydia lipopolysaccharide-IgA (LPS-IgA) seropositivity and elevated levels of interferon-gamma (IFN- $\gamma$ ), interleukin- 10 (IL-10), tumor necrosis factor-alpha (TNF- $\alpha$ ), soluble vascular cell adhesion molecule (sVCAM-1) and soluble Eselectin(sE-selectin) in CHD patients that might indicate persistent Chlamydia infection and a proinflammatory state $[5,20,21]$.

On the contrary, several other studies have failed to proof the association of Ch. Pneumoniae infection with CHD $[22,23,24]$. Therefore, a third opinion suggest that establishing a causal relationship between $C h$. peumoniae infection and cardiovascular disease requires more prospective studies with combination of techniques and stratified by etiological subtypes [25].

\section{Subjects and Methods}

The present study is a cross sectional case control study. It was conducted in Baqubah- Diyala province during the period from November / 2013 to December / 2014, and approved by the Diyala Health Directorate, Department of Research and Development. Informed consents were obtained from all participants, certain demographic factors and information of risk factors of CHD such as age, gender, and previous history of CHD, hypertension, diabetes mellitus and status of smoking was collected from patients by short personal interview. The study included 91 participants were divided into two groups; the patient group, consist of 45 patients with CHD (myocardial infarction, angina, atherosclerosis) who were chosen according to clinical criteria. They were either inpatients admitted to Baqubah General Teaching Hospital or outpatients attending the outpatient' clinic. The mean age was $(59.20 \pm 11.45)$ years with an age rang (40-90) years. The healthy control group, includes 46 healthy individuals of both sexes, selected randomly, the mean age was $(35.43 \pm 8.67)$ years with an age rang (32-86) years. Three milliliters of venous blood was drawn from each participant by vein punctures in plan plastic tubes. Sera were separated by centrifugation at 3000 rotation / minute for 5 minutes, and stored frozen until examination. Detection of anti- Ch. pneumoniae $\operatorname{IgG}$ and $\operatorname{IgA}$ antibodies was done by Enzyme - Linked Immunosorbant Assay (Nova Tec immundiagnostica GmbH, Germany). Testing procedure and interpretation of the results were followed the manufacturer's instructions. Statistical analysis was performed using SAS version -11 Ed. (Inc, Cary, NC, USA).Chi-square test was used to compare between patients and controls, $\mathrm{P}$ value of $<0.05$ was considered significance.

\section{Results}

Ninety one participants were included in this study. The mean age \pm SD of the patients was $59.20 \pm 11.45$ years, with age range $40-90$ years. The mean age \pm SD of the healthy controls was $35.43 \pm 8.67$ years, with age range 32-86 years. The seropositivity of anti- Ch. pneumoniae IgG antibodies among study groups revealed that $30(66.67 \%)$ patients and $25(54.35 \%)$ of healthy control were positive with a statistically significant difference between the two groups $(\mathrm{P}<0.05)$, table $(1)$.

Table 1. Seropositivity of anti-Chl. pneumoniae IgG antibodies among study groups

\begin{tabular}{llllll}
\hline \multirow{2}{*}{$\begin{array}{l}\text { Study } \\
\text { participants }\end{array}$} & \multicolumn{2}{l}{ Anti- Chlamydia pneumoniae IgG antibodies } & \multirow{2}{*}{ Total } \\
\cline { 2 - 5 } & \multicolumn{2}{l}{ Positive (\%) } & \multicolumn{2}{c}{ Negative (\%) } & \\
\hline Patients & 30 & 66.67 & 15 & 33.33 & 45 \\
Controls & 25 & 54.35 & 21 & 45.65 & 46 \\
Total & 55 & & 36 & & 91 \\
\hline
\end{tabular}

$\mathrm{P}<0.05[\mathrm{~S}]$

The seropositivity of anti- Ch. pneumoniae IgA antibodies among study groups was revealed in table (2). 11 (24.44\%) patients and $6(13.04 \%)$ healthy controls were positive, with a statistically significant difference between the two groups, $\mathrm{P}<0.05$.

Table 2. Seropositivity of anti-Chl. pneumoniae IgA antibodies among study groups

\begin{tabular}{llllll}
\hline \multirow{2}{*}{$\begin{array}{l}\text { Study } \\
\text { participants }\end{array}$} & \multicolumn{2}{l}{ Anti- Chlamydia pneumoniae IgG antibodies } & \multirow{2}{*}{ Total } \\
\cline { 2 - 4 } & Positive (\%) & \multicolumn{3}{c}{ Negative (\%) } & \\
\hline Patients & 11 & 24.44 & 34 & 75.56 & 45 \\
Controls & 6 & 13.04 & 40 & 86.96 & 46 \\
Total & 17 & & 74 & 91 \\
\hline
\end{tabular}

$\mathrm{P}<0.05[\mathrm{~S}]$

\section{Discussion}

Coronary heart disease is caused by multiple factors. A part from the role of conventional risk factors for cardiac disease, Ch. pneumoniae has been proposed to be one of the infectious causative factors [26,27].Association between Chlamydia pneumoniae and coronary heart disease has been detected by both seroepidemiological studies and by direct detection of the microorganism in atherosclerotic lesion, most of these studies reported propose an association but few studies reported negative results, this study which conducted in Diyala province, Iraq, by using ELIZA technique, is one of the recent studies that confirmed the association between Chlamydia pneumoniae and CHD [6]. The present results 
showed that the seropositivity rate of anti- Ch. pneumoniae $\mathrm{IgG}$ and $\operatorname{IgA}$ antibodies was significantly higher among patients compared to healthy controls. Many studies in the literature reported different results, the present results are consistent with previous studies; Ali et al., [28], demonstrated by using microimmunofluorescence technique, a rise in Chl. pneumoniae IgG antibodies levels among CHD patients. In Iran, Azarkar et al., [29], found that the prevalence of anti- Chl. pneumoniae IgG antibodies was 63 (71.9\%) among patients with acute myocardial infarction and 23(46.9\%) in control group $(\mathrm{P}<0.01)$. Ashkenazi et al., [30], suggested that chronic $C h$. pneumoniae infection play a role in the pathogenesis of atherosclerosis and acute ischemic event when they found a high titer of $\operatorname{IgG}$ antibody in patients with acute myocardial infarction compared to controls. In Saudi Arabia, Momenah and Tayeb, [31], reported that $C h$. pneumoniae infection play an important role in increase of CHD in the Saudi community when they found a significant correlation between anti- $C h$. pneumoniae IgG antibodies and CHD. Additionally, In a study conducted in India, Agarwal et al., [6], reported that the seroprevalence of anti- Ch. pneumoniae IgG antibodies was a significant higher among patients (76\%) with CAD in a compared to controls (59\%). Similarly, In Italy, Monno et al., [32], found by using microimmunofluorescence technique a high prevalence of $\operatorname{IgG}$ antibodies at titer $\geq 8$ was $(84 \%)$ among patients with cardiovascular disease compared to control group (47.6\%).

Regarding of anti- Chl. pneumoniae IgA antibodies, our results are concordant with many studies; for instance, Haider et al., [21], reported a high prevalence of anti- Chl. pneumoniae $\operatorname{IgA}$ antibodies was detected among patients with CHD (66.66\%) in comparison with control group (14.37\%). In Japanese study, Sakurai-Komada et al., [33], showed a high positivity of anti- Chl. pneumoniae IgA antibodies associated with a risk of CHD, specifically among myocardial infarction patients. Likewise, other studies found a strong association between CHD and anti- Ch. pneumoniae IgA antibodies [34]. Arcari et al., [34], found a significantly higher risk of AMI in patients who had high titers to $C h$. Pneumoniae immunoglobulin A (IgA).

\section{Conclusion}

The present results supports the contention of positive association of Ch. Pneumoniae infection and the development of CHD and suggest the need for a new medical visions to demonstrate the effect of $C h$. pneumoniae on the pathogenesis of coronary heart disease.

\section{Acknowledgement}

The authors would like to thank the professor Abul-Razak Shafiq Hasan, College of Medicine and for his support, and to Diyala Health Directorate in Diyala province for their support.

\section{References}

[1] Ward, M.E. Chlamydia. In: Greenwood, D.; Slack, R.; Peutherer, J. and Barer, M. Medical Microbiology. $17^{\text {th }}$. Ed 2007. Churchill Livingstone. PP 375-84.

[2] Saikku, P. ; Leinonen, M. ; Tenkanen, L. ; Linnanmaki, E. ; Ekman, M. R. ; et al. Chronic Chlamydia pneumoniae infection as a risk factor for coronary heart disease in the Helsinki Heart Study. Ann Intern Med. 1992;116: 273-278.

[3] Patel, P. ; Kendall, M. A. Carrington, D. et al. Association of Helicobacter pylori and Chlamydia pneumoniae infections with coronary heart disease. BMJ. 1995;311:711-14.

[4] World Health Organization. Global status report on noncommunicable diseases 2014. Geneva-Switzerland.

[5] Malinverni, R. Infective Chlamydia pneumoniae and coronary disease: where is the truth?. Rev. Med. Suisse Romande. 2000;120(1):43-6.

[6] Ieven, M. M. and Hoymans, V. Y. Involvement of Chlamydia pneumoniae in Atherosclerosis: More Evidence for Lack of Evidence.J. Clin. Microbiol. 2005;43(1): 19-24.

[7] Agarwal, L. A.; Chander, C. Y. and Nagendra, B. A. Serological evidence of chronic Chlamydia pneumoniae infection in coronary heart disease. MJAFI. 2007; 63: 229-32.

[8] Altannavch, T.S. ; Roubalova, K .; Broz, J. ; Hruba, D. and Andel, M. Serological markers of Chlamydia pneumoniae, cytomegalovirus and Helicobacter pylori infection in diabetic and non-diabetic patients with unstable angina pectoris. Cent. Eur. J. Publ. Health. 2003;11(2):102-6.

[9] Jha, H.C .; Prasad, J. and Mittal, A. High immunoglobulin A seropositivity for combined Chlamydia pneumoniae, Helicobacter pylori infection, and high-sensitivity C-reactive protein in coronary artery disease patients in India can serve as atherosclerotic marker. Heart Vessels. 2008;23(6):390-6.

[10] Al-Ghamdi, A. ; Jiman-Fatani, A.A. and El-Banna, H. Role of Chlamydia pneumoniae,helicobacter pylori and cytomegalovirus in coronary artery disease. Pak. J. Pharm. Sci. 2011;24(2):95-101.

[11] Grdanoska, T. ; Zafirovska, P. ; Jaglikovski, B. ; Pavlovska, I. ; Zafirova, B. ; Tosheska-Trajkovska, K. ; Trajkovska-Dokic, E. ; Petrovska, M. ; Cekovska, Z. ; Kondova-Topuzovska, I. ; Georgievska-Ismail, L. and Panovsk,i N. Chlamydia pneumoniae and helicobacter pylori serology - importance in patients with coronary heart disease. Mater Sociomed. 2012;24(3):151-6.

[12] Kazar, J.; Kovacova, E.; Koncova, K.; Cvachova, S.; Mongiellova, V.; Lietava, J. and Simko, F. Chlamydia pneumoniae antibodies and markers of inflammation in patients with cardiovascular diseases. Bratisl Lek Lisly. 2005;106(11):341-4.

[13] Romano Carratelli, C.; Nuzzo, I. ; Cozzolino, D. ; Bentivoglio, C.; Paolillo, R. and Rizzo, A. Relationship between Chlamydia pneumoniae infection, inflammatory markers, and coronary heart diseases. Int. Immunopharmacol. 2006;6(5):848-53.

[14] Pesonen, E. ; Andsberg, E. ; Ohlin, H. ; Puolakkainen, M. ; Rautelin, H. ; Sarna, S. and Persson, K. Dual role of infections as risk factors for coronary heart disease. Atherosclerosis. 2007;192(2):370-5. 
[15] Piechowski-Jozwiak, B. ; Mickielewicz, A. ; Gaciong, Z. ; Berent, H. and Kwiecinski, H. Elevated levels of antiChlamydia pneumoniae $\operatorname{IgA}$ and $\operatorname{IgG}$ antibodies in young adults with ischemic stroke. Acta Neurol Scand. 2007;116(3):144-9.

[16] Latsios, G. ; Saetta, A. ; Michalopoulos, N.V. ; Agapitos, E. and Patsouris, E. Detection of cytomegalovirus, Helicobacter pylori and Chlamydia pneumoniae DNA in carotid atherosclerotic plaques by the polymerase chain reaction. Acta Cardiol. 2004;59(6):652-7.

[17] Jha, H.C. and Mitta, I. A. Sequencing of Chlamydia pneumoniae in coronary artery disease patients attending tertiary hospital in India. Am. J. Infect. Control. 2010;38(6):497-8.

[18] Gurfinked, E. and Bozovich, G. Chlamydia pneumoniae : Inflammation and instability of atherosclerotic plaque. Atherosclerotic. 1998;140 [Suppl 1]: S31-35.

[19] Guech-Ongey, M. ; Brenner, H.; Twardella, D. and Rothenbacher, D. Chlamydia pneumoniae, heat shock proteins 60 and risk of secondary cardiovascular events in patients with coronary heart disease under special consideration of diabetes: a prospective study. BMC Cardiovasc. Disord. 2006;6:17.

[20] Schumacher, A. ; Seljeflot, I. ; Lerkerod, A.B.; Sommervoll, L. ; Otterstad, J.E. and Arnesen, H. Chlamydia LPS and MOMP seropositivity are associated with different cytokine profiles in patients with coronary heart disease. Eur. J. Clin. Invest. 2005;35(7):431-7.

[21] Haider, M. ; Rizvi, M. ; Malik, A. ; et al. Acute and chronic Chlamydia pneumoniae infection and inflammatory markers in coronary heart disease patients. J. Infect. Dev. Ctries. 2011;5(8): 580-6.

[22] Tanne, D. ; Haim, M. ; Boyko, V. ; Goldbourt, U.; Reshef. T. ; Adler, Y.; Brunner, D.; Mekori, Y.A. andBehar, S. Prospective study of Chlamydia pneumoniae IgG and IgA seropositivity and risk of incident ischemic stroke. Cerebrovasc. Dis. 2003;16(2):166-70.

[23] Chaudhury, A.; Rajasekhar, D. ; Latheef, S.A. and Subramanyam, G. Seroprevalence of $\mathrm{IgG}$ antibodies to Chlamydia pneumoniae and Helicobacter pylori among coronary heart disease patients and normal individuals in South Indian population. Indian J. Pathol. Microbiol. 2004;47(3):433-4.
[24] Vainas, T. ; Sayed, S. ; Bruggeman, C.A. and Stassen, F.R. Exploring the role of Chlamydia pneumoniae in cardiovascular disease: a narrative review. Drug Today (Brac) 2009;45 Suppl B:165-72.

[25] Chen, J. ; Zhu, M. ; Ma, G. ; Zhao, Z. and Sun, Z. Chlamydia pneumoniae infection and cerebrovascular disease: a systematic review and meta-analysis. BMC Neurol. 2013;13:183.

[26] Kurano, M. and Tsukamoto, K. Etiology of atherosclerosis-special reference to bacterial infection and viral infection. Nihon Rinsho. 2011;69(1):25-9

[27] Zodpey, S. P. ; Shrikhande, S. N. ; Negandhi, H. N. ; Ughade, S. N. ; Joshi, P. P. Risk factors for acute myocardial infarction in central India. Indian J Community Med. 2015;40(1):19-26.

[28] Ali, H. A. ; Al-Humrani, A. H. and Al-Hadithi, H. T. Chlamydia pneumoniae infection in coronary heart disease in Basrah. The Medical Journal of Basrah University. 2010;25(1) : 23-6.

[29] Azarkar, Z. ;Jafarnejad, M. ; Zardast, M. ; et al. Chlamydia pneumoniae infection and cardiac risk factors in patients with myocardial infection. ARYA Atherosclerosis Journal. 2011;6(4): 127-30.

[30] Ashkenazi, H. ; Rudensky, B. ; Paz, E. ; Raveh. D. ; Balkin, J. A.; et al. Incidence of Immunoglobulin $G$ antibodies to Chlamydia pneumoniae in acute myocardial infarction patients. IMAJ. 2001;3: 818-21.

[31] Momenah, A.M. and Tayeb, M.T. Chlamydia pneumoniae seropositivity and risk of developing coronary heart disease in Western Saudi Arabia. Saudi Med. J. 2005;26(12):1926-9.

[32] Monno, R. ;Fumarola, L. ; Trerotoli, P. ; Giannelli, G. ; Correale, M. ; et al. Seroprevalence of Chlamydophila pneumoniae in ischaemic heart disease. New Microbiologia. 2010;33: 381-385.

[33] Sakurai-Komada, N. ; Iso, H. ; Kaike, K. A. ; Ikeda, A. ; Umesawa, M. ; et al. Association between Chlamydophila pneumoniae infection and risk of coronary heart disease for Japanese : the JPHCN study. Atherosclerosis. 2014;233(2) : 338-42.

[34] Arcari, C. ; Gaydos, C. ; Nieto, F. ; et al. Association between Chlamydia pneumoniae and acute myocardial infarction in young men in the united states military: the importance of timing of exposure measurement. Clin Infect Dis. 2005;40:1123-1132. 